\title{
openheart Performing diagnostic radial access coronary angiography on uninterrupted direct oral anticoagulant therapy: a prospective analysis
}

\author{
Napohn Chongprasertpon, ${ }^{\top 1}$ Aiste Zebrauskaite, ${ }^{1}$ John Joseph Coughlan, ${ }^{\oplus 1}$ \\ Abdalla Ibrahim, ${ }^{1}$ Samer Arnous, ${ }^{2}$ Terence Hennessy, ${ }^{1}$ Thomas John Kiernan ${ }^{1}$
}

To cite: Chongprasertpon N, Zebrauskaite A, Coughlan JJ, et al. Performing diagnostic radial access coronary angiography on uninterrupted direct oral anticoagulant therapy: a prospective analysis. Open Heart 2019;6:e001026. doi:10.1136/

openhrt-2019-001026

$\mathrm{NC}$ and $\mathrm{AZ}$ contributed equally.

Received 2 February 2019 Revised 17 April 2019 Accepted 18 April 2019

\section{Check for updates}

C) Author(s) (or their employer(s)) 2019. Re-use permitted under CC BY-NC. No commercial re-use. See rights and permissions. Published by BMJ.

${ }^{1}$ Cardiology, University Hospital Limerick, Dooradoyle, Ireland ${ }^{2}$ Cardiology, Rigshospitalet, Copenhagen, Denmark

Correspondence to Dr Napohn Chongprasertpon; napohn@gmail.com

\section{ABSTRACT}

Purpose We sought to assess the safety of performing diagnostic radial access coronary angiography with uninterrupted anticoagulation on patients receiving direct oral anticoagulant therapy.

Background Direct oral anticoagulants have become a popular choice for the prevention of thromboembolism. Risk factors for thromboembolism are common among cardiovascular conditions and indications for direct oral anticoagulant therapy as well as coronary angiography often overlap in patients. It has been hypothesised that uninterrupted direct oral anticoagulant therapy would increase haemorrhagic and access site complications, however data in this area is limited.

Methods This was a prospective observational analysis of 49 patients undergoing elective diagnostic coronary angiography while receiving uninterrupted anticoagulation with direct oral anticoagulants. This population was compared with a control group of 49 unselected patients presenting to the cardiology service for elective diagnostic coronary angiography. Continuous variables were analysed using the independent samples t-test and categorical variables using Pearson's $\chi^{2}$ test.

Results The mean duration of radial compression for the control group was $235.8 \pm 62.8 \mathrm{~min}$ and for the uninterrupted direct oral anticoagulant group was $258.4 \pm 56.5 \mathrm{~min}$. There was no significant difference in mean duration of radial compression $(p=0.07 ; 95 \%$ $\mathrm{Cl}=-1.4$ to 46.5$)$. There was also no difference in the complication rate between the two groups $(p=1)$.

Conclusions We observed similar complication rates and radial artery compression time postangiography in both groups. This small prospective observational study suggests that uninterrupted continuation of direct oral anticoagulants during coronary angiography is safe. Larger randomised control studies in this area would be beneficial.

\section{INTRODUCTION}

In recent years direct oral anticoagulants (DOACs) have become a popular choice for the prevention and management of thromboembolism, and it is estimated that one in six patients on DOACs will undergo an invasive

\section{Key messages}

What is already known about this subject?

- Uninterrupted anticoagulation with warfarin therapy in patients undergoing coronary angiography appears to be safe in selected patients without risk factors for bleeding. The use of direct oral anticoagulants in place of vitamin $\mathrm{K}$ antagonists has grown substantially.

What does this study add?

- This prospective observational analysis compared a control group of unselected patients presenting to our service for elective diagnostic coronary angiography through radial access with a study group of patients who received uninterrupted anticoagulation with direct oral anticoagulant therapy pericoronary angiography. This provides insight into the feasibility of continuing direct oral anticoagulants uninterrupted during elective diagnostic coronary angiography.

How might this impact on clinical practice?

- Our study suggests that uninterrupted continuation of direct oral anticoagulants during radial access coronary angiography can be performed safely with similar complication rates and radial artery compression time to patients not receiving direct oral anticoagulant therapy. Our work identifies the need for larger randomised studies in this interesting area.

procedure every year. ${ }^{1}$ Discontinuation of anticoagulation prior to interventional procedures such as coronary angiography had been an accepted practice in the past. ${ }^{2}$ It was assumed that continuation of anticoagulation would increase haemorrhagic and access site complications. ${ }^{3}$ However, much research has been published in the last decade on the use of continuous uninterrupted anticoagulation with warfarin therapy in patients undergoing coronary angiography. ${ }^{2-7}$ Many studies reached the conclusion that angiography with uninterrupted warfarin therapy 
was safe or appeared safe in selected patients and that it was an alternative for consideration. ${ }^{36} 6$ Two meta-analyses reported that uninterrupted anticoagulation with warfarin appeared safe but that further evidence in the form of randomised control trials were needed. ${ }^{2}{ }^{7}$ The recent American College of Cardiology (ACC) expert consensus suggested that procedures with low bleed risk can be performed on patients in the absence of patient related factors that increase risk of bleeding without interrupting anticoagulation therapy for more than 24 hours. ${ }^{8}$ With the advent of DOACs being used in place of vitamin $\mathrm{K}$ antagonists the feasibility of continuing DOACs uninterrupted during coronary angiography deserves investigation.

Beyer-Westendorf et al performed a study of periprocedural DOAC management for invasive procedures ranging from minimal procedures such as skin biopsies to major procedures such as thoracic surgery. ${ }^{9}$ This study suggested that continuation of DOAC was safe for most invasive procedures. ${ }^{9}$ The data from Beyer-Westendorf $e t$ $a l$ which included coronary angiography as well as other procedures showed that patients who underwent elective procedures with DOACs uninterrupted had no major bleeding and experienced clinically relevant non-major bleed rate of less than $5 \% .{ }^{9}$ However, concerns remain with regard to the potential increased haemorrhagic risk during coronary angiography. Any risk of bleeding needs to be weighed and balanced against the risk of thrombosis associated with interruption of DOAC. In addition to this, there have been anecdotal reports of "rebound hypercoagulability" after DOAC discontinuation. ${ }^{10}{ }^{11}$ One study suggested that low concentrations of dabigatran enhanced thrombin generation and hypercoagulability. ${ }^{12}$ Another study reported the hazard of a thromboembolic event to be nearly seven times greater in the first month after discontinuing DOACs than in the second and subsequent months when the hazard returned to the $\mathrm{CHADS}_{2}$ score-predicted level. ${ }^{13}$

As mentioned previously, there is a dearth of data on uninterrupted DOAC therapy during coronary angiography compared with uninterrupted warfarin therapy. As such, we set out to investigate whether it is safe to perform diagnostic coronary angiography while continuing anticoagulation with DOACs.

\section{METHODS}

This was a prospective observational study of 49 patients undergoing elective diagnostic coronary angiography while receiving uninterrupted anticoagulation with DOACs at University Hospital Limerick. Elective patients presenting for diagnostic coronary angiography and receiving DOAC therapy were recruited consecutively and consent for inclusion in the study was obtained prior to the procedure. Patients had taken their regular dose of DOAC within 24 hours prior to the procedure.

Data was collected on a standardised pro-forma by specialist cardiology doctors and nurses in our cardiac catheterisation laboratory. The data collected on this pro-forma included age, sex, serum creatinine, estimated glomerular filtration rate (eGFR), $\mathrm{CHA}_{2} \mathrm{DS}_{2}$-VASc score, HAS-BLED score, relevant medical history, ECG rhythm, relevant medications, angiogram access site approach, periprocedural complications and duration of radial artery compression. The early ( $<12$ hours) postprocedural complications listed on the pro-forma included prolonged access site pressure ( $>6$ hours), access site bleeding, hematoma, major haemorrhage, minor haemorrhage, arterial dissection/perforation, arteriovenous fistula, pseudoaneurysm, arterial thrombus and stroke/ transient ischaemic attack (TIA).

Major and minor bleeding was classified according to the thrombolysis in myocardial infarction (TIMI) criteria. ${ }^{14}$ Bleeding was defined as major if it was intracranial, associated with a haemoglobin decrease of $>50$ $\mathrm{g} / \mathrm{L}$ or a haematocrit decrease of $>15 \%$. Minor bleeding was defined as a haemoglobin decrease of $>30 \mathrm{~g} / \mathrm{L}$ or a haematocrit decrease of $>10 \%$ in cases of observed haemorrhaging. If haemorrhaging was not observed despite efforts to identify it then a minor bleed was defined as a decrease in haemoglobin $>40 \mathrm{~g} / \mathrm{L}$ or a decrease in haematocrit $>12 \%$. Bleeding events were detected by specialist cardiology nurses and the decision regarding fulfilment of TIMI criteria was made by the doctors working in the cardiology day ward. None of the authors were involved in adjudication of bleeding events.

Our study population was compared with a control group of 49 standard patients. This control group were unselected patients presenting to our cardiology service for elective diagnostic coronary angiography through the radial access route. As such, patients were excluded from the study if their coronary angiogram was performed via a transfemoral approach. Ad hoc percutaneous coronary intervention (PCI) is not routinely performed for elective day case diagnostic coronary angiography patients at our centre. Patients were excluded from the study if they underwent ad hoc PCI.

Patients had coronary angiography performed with either a 4, 5 or 6 Fr sheath. Patients in the control group received a standard cocktail of $2.5 \mathrm{mg}$ of verapamil and 3000-5000 units of unfractionated heparin (UFH) according to operator protocol. None of the patients in the DOAC uninterrupted group received UFH during the procedure and only verapamil was given as a $2.5 \mathrm{mg}$ bolus for this group. Radial artery compression was performed with devices, namely the SafeGuard Radial Compression Device (Merit Medical) and TR Band Radial Compression Device (Terumo Interventional Systems) which were used in our study at the discretion of the operator. The time until radial compression device removal was recorded by nursing staff on our management of radial compression device form as per local protocol. This was defined as the time from application of the radial compression device in the cardiac catheterisation laboratory until the radial compression device was released. The radial compression devices were deflated based on our standardised 
Table 1 Age and sex characteristics of both the uninterrupted DOAC cohort and the control group

\begin{tabular}{|c|c|c|c|}
\hline \multicolumn{4}{|c|}{ Age and sex characteristics } \\
\hline Variable & $\begin{array}{l}\text { DOAC } \\
\text { uninterrupted } \\
(n=49)\end{array}$ & Control $(n=49)$ & $P$ value \\
\hline Age (years) & $66.9 \pm 11.3$ & $61.7 \pm 10.8$ & 0.02 \\
\hline Male sex (\%) & 75.5 & 73.5 & 0.82 \\
\hline
\end{tabular}

DOAC, direct oral anticoagulant.

postangiogram protocol by specialist cardiac catheterisation laboratory trained nursing staff.

Continuous variables were analysed using the independent samples t-test and categorical variables were analysed using the Pearson's $\chi^{2}$ test. Analyses were performed using IBM SPSS Statistics V.20. $\mathrm{P}<0.05$ was considered statistically significant for all results.

\section{RESULTS}

\section{Baseline demographics}

The DOAC uninterrupted group and the control group had similar characteristics in terms of gender distribution at approximately $75 \%$ of patients being male $(p=0.82)$ (table 1). Patients in the DOAC uninterrupted group had a mean age of $66.9 \pm 11.3$ years while the control patients had a mean age of $61.7 \pm 10.8$ years (table 1 ). This represents approximately a 5-year difference with the DOAC uninterrupted group being slightly older than the control group $(\mathrm{p}=0.02)$ (table 1$)$.

Most of the patients in the DOAC uninterrupted group had low HAS-BLED scores with a mean of $1.2 \pm 1$ while mean $\mathrm{CHAD}_{2} \mathrm{~S}_{2}$-VASc score was 2.9 \pm 1.6 (table 2).

Mean eGFR of $75.9 \pm 19.3 \mathrm{~mL} / \mathrm{min}$ and only $10.2 \%$ of patients had documented chronic kidney disease (table 2). There was a high prevalence of hypertension at $59.2 \%$ (table 2 ). Only $6.1 \%$ of patients had a previous stroke or TIA and no patients had documented chronic liver disease (table 2). The majority of patients had an ECG record of atrial fibrillation at $80.4 \%$ (table 2).

Rivaroxaban and apixaban were the most common DOACs used in the DOAC uninterrupted group at $57.1 \%$ and $32.7 \%$ respectively (table 2 ). Edoxaban and dabigatran were also used at $6.1 \%$ and $4.1 \%$ respectively (table 2). At $18.4 \%$, nearly one in five patients were receiving aspirin in addition to the DOAC therapy (table 2). $6.1 \%$ of the DOAC uninterrupted group were taking an ADP receptor antagonist and $4.1 \%$ of patients were taking triple oral anti-thrombotic therapy (DOAC, aspirin and an ADP receptor antagonist) (table 2).

\section{Procedural characteristics}

All patients in both the control and DOAC uninterrupted groups underwent coronary angiography through a radial approach (table 3). A 5 Fr sheath was used in $86 \%$ of control cases and a $6 \mathrm{Fr}$ in the remaining 14\% (table 3). For the DOAC uninterrupted group a $4 \mathrm{Fr}$ sheath was used
Table 2 Baseline characteristics of patients receiving angiography with continuous DOAC therapy

\section{Baseline characteristics}

\begin{tabular}{|c|c|}
\hline Variable & $\begin{array}{l}\text { DOAC uninterrupted } \\
(\mathrm{n}=49)\end{array}$ \\
\hline Creatinine ( $\mu \mathrm{mol} / \mathrm{L})$ & $87 \pm 26.23$ \\
\hline eGFR (Cockcroft-Gault) (mL/min) & $75.9 \pm 19.3$ \\
\hline eGFR $\geq 60(\%)$ & 81.6 \\
\hline eGFR 30-59 (\%) & 16.3 \\
\hline eGFR <30 (\%) & 2 \\
\hline $\mathrm{CHAD}_{2} \mathrm{~S}_{2}-\mathrm{VASc}$ score & $2.9 \pm 1.6$ \\
\hline HAS-BLED score & $1.2 \pm 1$ \\
\hline $\begin{array}{l}\text { ECG atrial fibrillation (paroxysmal or } \\
\text { permanent) (\%) }\end{array}$ & 80.4 \\
\hline \multicolumn{2}{|l|}{ Medical history } \\
\hline Congestive cardiac failure (\%) & 22.4 \\
\hline Controlled hypertension (\%) & 59.2 \\
\hline Uncontrolled hypertension (\%) & 0 \\
\hline Pulmonary hypertension (\%) & 0 \\
\hline $\begin{array}{l}\text { Vascular disease (including Ischaemic } \\
\text { heart disease) (\%) }\end{array}$ & 32.7 \\
\hline Previous stroke/TIA (\%) & 6.1 \\
\hline Venous embolism (\%) & 6.1 \\
\hline Mitral or aortic valve disease (\%) & 6.1 \\
\hline Aortic stenosis (\%) & 6.1 \\
\hline Kidney disease (\%) & 10.2 \\
\hline Liver disease (\%) & 0 \\
\hline Diabetes mellitus (\%) & 6.1 \\
\hline $\begin{array}{l}\text { Chronic obstructive pulmonary } \\
\text { disease (\%) }\end{array}$ & 2 \\
\hline Hypercholesterolaemia (\%) & 30.6 \\
\hline \multicolumn{2}{|l|}{ Type of DOAC therapy } \\
\hline Dabigatran (\%) & 4.1 \\
\hline Rivaroxaban (\%) & 57.1 \\
\hline Apixaban (\%) & 32.7 \\
\hline Edoxaban (\%) & 6.1 \\
\hline \multicolumn{2}{|l|}{ Other medications } \\
\hline Aspirin (\%) & 18.4 \\
\hline ADP inhibitor (\%) & 6.1 \\
\hline Aspirin with ADP inhibitor (\%) & 4.1 \\
\hline
\end{tabular}

$A D P$, adenosine diphosphate; DOAC, direct oral anticoagulant; TIA, transient ischaemic attack; eGFR, estimated glomerular filtration rate.

in $4 \%$ of patients, $5 \mathrm{Fr}$ in $82 \%$ and $6 \mathrm{Fr}$ in $14 \%$ (table 3 ). There was no statistical difference between the number of patients who had the procedure performed with a 5 Fr sheath in each group ( $p=0.56)$. UFH was not administered for any of the patients in the DOAC uninterrupted group. The control group received 3000-5000 units of 
Table 3 Procedural characteristics of both the uninterrupted DOAC cohort and the control group

\begin{tabular}{|c|c|c|c|}
\hline \multicolumn{4}{|c|}{ Procedural characteristics } \\
\hline Variable & $\begin{array}{l}\text { DOAC } \\
\text { uninterrupted } \\
(n=49)\end{array}$ & $\begin{array}{l}\text { Control } \\
(n=49)\end{array}$ & $P$ value \\
\hline \multicolumn{4}{|l|}{ Sheath size used } \\
\hline $4 \operatorname{Fr}(\%)$ & 4 & 0 & 0.49 \\
\hline $5 \mathrm{Fr}(\%)$ & 82 & 86 & 0.56 \\
\hline $6 \mathrm{Fr}(\%)$ & 14 & 14 & 1 \\
\hline $\begin{array}{l}\text { Duration of radial } \\
\text { compression (min) }\end{array}$ & $258.4 \pm 56.5$ & $235.8 \pm 62.8$ & 0.07 \\
\hline $\begin{array}{l}\text { Periprocedural } \\
\text { complications (\%) }\end{array}$ & 2 & 2 & 1 \\
\hline \multicolumn{4}{|l|}{$\begin{array}{l}\text { Early (<12 hours) } \\
\text { postprocedural } \\
\text { complications }\end{array}$} \\
\hline $\begin{array}{l}\text { Prolonged access site } \\
\text { pressure } \\
(>6 \text { hours) }(\%)\end{array}$ & 2 & 2 & 1 \\
\hline Access site bleeding (\%) & 0 & 0 & \\
\hline Haematoma (\%) & 0 & 0 & \\
\hline Major haemorrhage (\%) & 0 & 0 & \\
\hline Minor haemorrhage (\%) & 0 & 0 & \\
\hline $\begin{array}{l}\text { Arterial dissection/ } \\
\text { perforation (\%) }\end{array}$ & 0 & 0 & \\
\hline Arteriovenous fistula (\%) & 0 & 0 & \\
\hline Pseudoaneurysm (\%) & 0 & 0 & \\
\hline Arterial thrombus (\%) & 0 & 0 & \\
\hline Stroke/TIA (\%) & 0 & 0 & \\
\hline
\end{tabular}

DOAC, direct oral anticoagulant; TIA, transient ischaemic attack.

UFH at the discretion of the operator as per our usual practice. The mean duration of radial compression for the control group was $235.8 \pm 62.8 \mathrm{~min}$ and for the DOAC uninterrupted group was $258.4 \pm 56.5$ min (table 3 ). Mean difference in duration of radial compression between the two groups was $22.5 \mathrm{~min}$. Our $\mathrm{p}$ value showed no significant difference in mean duration of radial compression and our $95 \%$ CI for difference in duration included 0 ( $\mathrm{p}=0.07 ; 95 \% \mathrm{CI}=-1.4$ to 46.5 ) (table 3$)$. The range of $\mathrm{CI}$ for difference are less than the predefined zone of clinical indifference of 1 hour difference in duration.

\section{Study outcomes}

Only one patient in the DOAC group experienced a complication which was bleeding from the radial access site. This required prolonged access site pressure lasting 6 hours 10 min (table 3 ). This patient had a HAS-BLED score of 3 and was not receiving any antiplatelet therapy. The prolonged access site pressure achieved satisfactory haemostasis and the patient was discharged home with no further complications. Major and minor bleeds were defined according to the TIMI criteria ${ }^{14}$ and none occurred for any patient in the study (table 3 ). The control group also had one patient with the complication of bleeding requiring prolonged access site pressure which lasted 7 hours and 40 mins (table 3 ). This patient was also discharged home with no further complications. There were no other adverse events or major bleeds. Therefore, there was no difference in the complication rate between the DOAC uninterrupted group and the control group (table 3). Apart from the prolonged access site pressure, no other early postprocedural complications occurred in either group. No strokes/TIAs occurred in any patient (table 3).

\section{DISCUSSION}

Our small prospective observational analysis indicates it is feasible and safe to continue DOACs during day case radial coronary angiography. Our study suggests continuous anticoagulation with DOACs during coronary angiography is similar to our control group of standard patients presenting to our cardiology service with regard to radial artery compression times and rates of complications.

Our study has included the uninterrupted use of all four currently available DOACs pericoronary angiography. Our results are most relevant for rivaroxaban and apixaban as these were used in a greater proportion of our patients. However, it is likely that they can be applied to all commercially available DOACs.

The older age of the DOAC uninterrupted group compared with the control group of our study is not unexpected. This is because DOACs are now the predominant anticoagulant used in atrial fibrillation, ${ }^{15}$ a condition which increases in prevalence from less than $0.2 \%$ in those younger than 49 years of age up to $10 \%-17 \%$ in those aged 80 years or older. ${ }^{16}$

Similar to previous studies involving anticoagulation with warfarin, ${ }^{2-7}$ the results of our study suggest that continuation of DOAC is also safe with no major complications or bleeding as defined by the TIMI criteria. One of the studies using warfarin as the anticoagulant reported multiple bleeding complications including bleeding delaying discharge, pseudoaneurysm, need for corrective surgery and transfusion of blood products. ${ }^{4}$ It is noteworthy that this study only had a radial access approach of $56 \%$ which likely influenced the incidence of haemorrhagic complications. ${ }^{4}$ The lack of any haemorrhagic complications in the DOAC uninterrupted group of our study is a reassuring finding.

In the modern era of interventional cardiology, the majority of diagnostic coronary angiography in our centre is performed through the radial approach therefore minimising any haemorrhagic issues associated with femoral access. Our study was limited to radial access only and our results are therefore limited to trans-radial coronary angiography. We did not have follow-up to assess for radial artery occlusion (RAO) and this was a limitation to our study. Ideally, the reverse Barbeau's test and Doppler ultrasonography would be used to assess for 
RAO.$^{17}$ Future studies on continuation of DOAC during coronary angiography should consider evaluating radial artery patency postprocedure. Two different compression devices were used in our cath lab at the discretion of the operator which is another potential limitation. Other potential issues which our findings did not address are implications for those cases which need to switch to femoral access and even more so for those cases which need to proceed to PCI. Primary PCI is the treatment of choice for myocardial infarction in the emergency setting and would certainly be performed irrespective of whether the patient was receiving DOAC therapy.

Limitations to our statistical analysis are the small sample size which may not be sufficient to detect rarer complication events. It must also be acknowledged that there is inherent bias associated with not randomising patients in our study. The size and nature of our preliminary study would indicate that larger randomised control trials would be highly beneficial to further solidify the evidence base for continuing DOACs during coronary angiography.

As with warfarin, ${ }^{6}$ a considerable proportion of patients with an indication for DOACs are likely to also have an indication for coronary angiography. Risk factors are common among conditions such as stroke, atrial fibrillation, coronary artery disease and congestive cardiac failure. ${ }^{6}$ Hence, there is a substantial proportion of patients receiving diagnostic coronary angiography who are also receiving long term anticoagulation with DOACs.

Previous studies have discussed cost savings associated with continuation of warfarin therapy pericoronary angiography. ${ }^{24}$ The continuation of DOACs during coronary angiography would eliminate the need for patients to hold and restart the medication. There may be time and cost savings associated with liaising and organising the holding of DOACs with patients. However, the greatest benefit will of course lie in the significantly increased convenience and ease for patients.

\section{CONCLUSION}

This small prospective observational study suggests that uninterrupted continuation of DOACs during radial access coronary angiography results in similar complication rates and radial artery compression time to our control cohort of day case patients not on DOAC therapy. Larger, randomised studies in this area would be of great interest and clinical benefit.

Contributors NC performed all statistical analyses and drafted the manuscript. AZ was responsible for the conception and design of the study as well as gathering of all data. AZ is co-first author. The manuscript was revised by JJC and AI. Final approval of the version published was given by SA, TH and TJK. All authors are in agreement regarding the manuscript.

Funding The authors have not declared a specific grant for this research from any funding agency in the public, commercial or not-for-profit sectors.

Competing interests None declared.

Patient consent for publication Not required.
Ethics approval All procedures performed in studies involving human participants were in accordance with the ethical standards of the institutional and/ or national research committee and with the 1964 Helsinki declaration and its later amendments or comparable ethical standards. This article does not contain any studies with animals performed by any of the authors. Ethical approval was received prior to commencing this study from the HSE Mid-West ethics committee.

Provenance and peer review Not commissioned; externally peer reviewed.

Data sharing statement No data are available.

Open access This is an open access article distributed in accordance with the Creative Commons Attribution Non Commercial (CC BY-NC 4.0) license, which permits others to distribute, remix, adapt, build upon this work non-commercially, and license their derivative works on different terms, provided the original work is properly cited, appropriate credit is given, any changes made indicated, and the use is non-commercial. See: http://creativecommons.org/licenses/by-nc/4.0/.

\section{REFERENCES}

1. Lijfering WM, Tichelaar YIGV. Direct oral anticoagulant use and risk of perioperative bleeding: evidence of absence or absence of evidence? Res Pract Thromb Haemost 2018;2:182-5.

2. Ahmed I, Gertner E, Nelson WB, et al. Safety of coronary angiography and percutaneous coronary intervention in patients on uninterrupted warfarin therapy: a meta-analysis. Interv Cardiol 2011;3:101-9.

3. Karjalainen PP, Vikman S, Niemelä M, et al. Safety of percutaneous coronary intervention during uninterrupted oral anticoagulant treatment. Eur Heart J 2008;29:1001-10.

4. Annala A-P, Karjalainen PP, Porela P, et al. Safety of diagnostic coronary angiography during uninterrupted therapeutic warfarin treatment. Am J Cardiol 2008;102:386-90.

5. Wang TKM, Snow TAC, Watson T, et al. Anticoagulated patients undergoing coronary angiography: continue or Discontinue warfarin? Heart Lung Circ 2013;22.

6. Jessup DB, Coletti AT, Muhlestein JB, et al. Elective coronary angiography and percutaneous coronary intervention during uninterrupted warfarin therapy. Cathet. Cardiovasc. Intervent. 2003;60:180-4

7. Jamula E, Lloyd NS, Schwalm J-D, et al. Safety of uninterrupted anticoagulation in patients requiring elective coronary angiography with or without percutaneous coronary intervention: a systematic review and metaanalysis. Chest 2010;138:840-7

8. Doherty JU, Gluckman TJ, Hucker WJ, et al. 2017 ACC expert consensus decision pathway for periprocedural management of anticoagulation in patients with nonvalvular atrial fibrillation: a report of the american college of cardiology clinical expert consensus document task force. J Am Coll Cardiol 2017;69:871-98.

9. Beyer-Westendorf J, Gelbricht V, Förster K, et al. Peri-interventional management of novel oral anticoagulants in daily care: results from the prospective Dresden NOAC registry. Eur Heart $J$ 2014;35:1888-96.

10. Nagasayi S, Varman S, Ting YY, et al. Rivaroxaban withdrawal and rebound hypercoagulability leading to upper extremity deep vein thrombosis: a case report. Age Ageing 2017;46:870-1.

11. Bakhit A, Selim A, Fatima U, et al. Rebound thrombosis within 24hours after interruption of therapy with rivaroxaban. Int $J$ Cardiol 2016;212:235-6.

12. Perzborn E, Heitmeier S, Buetehorn U, et al. Direct thrombin inhibitors, but not the direct factor Xa inhibitor rivaroxaban, increase tissue factor-induced hypercoagulability in vitro and in vivo. $J$ Thromb Haemost 2014;12:1054-65.

13. Vene N, Mavri A, Gubenšek M, et al. Risk of Thromboembolic events in patients with non-valvular atrial fibrillation after dabigatran or rivaroxaban discontinuation - data from the ljubljana registry. PLoS One 2016;11:e0156943.

14. Rao AK, Pratt C, Berke A, et al. Thrombolysis in Myocardial Infarction (TIMI) Trial--phase I: hemorrhagic manifestations and changes in plasma fibrinogen and the fibrinolytic system in patients treated with recombinant tissue plasminogen activator and streptokinase. J Am Coll Cardiol 1988;11:1-11.

15. Gadsbøll K, Staerk L, Fosbøl EL, et al. Increased use of oral anticoagulants in patients with atrial fibrillation: temporal trends from 2005 to 2015 in Denmark. Eur Heart J 2017;38:899-906.

16. Zoni-Berisso M, Lercari F, Carazza T, et al. Epidemiology of atrial fibrillation: European perspective. Clin Epidemiol 2014;6:eCollection 2014:213-20.

17. Avdikos G, Karatasakis A, Tsoumeleas A, et al. Radial artery occlusion after transradial coronary catheterization. Cardiovasc Diagn Ther 2017;7:305-16. 